\title{
Os processos de subjetivação e seus efeitos no atendimento focado no desenvolvimento profissional
}

The processes of subjectivation and their effects on service focused on professional development

Los procesos de subjetivación y sus efectos en la atención con foco en el desarrollo profesional

\author{
Allanderson de Oliveira Batista* \\ Roberta Carvalho Romagnoli*
}

\begin{abstract}
Resumo
Este texto pretende problematizar os processos de subjetivação e seus efeitos no atendimento focado no desenvolvimento profissional, que tem como público gestores de equipes que trabalham em empresas de Engenharia, no segmento de construção pesada. Apresentamos o mercado de construção pesada com algumas de suas especificidades e utilizamo-nos do método da cartografia para tentar rastrear os processos de subjetivação que ocorrem entre o consultor e o seu cliente na relação que se estabelece. Procuramos problematizar, por meio da nossa experiência, dos dados de pesquisa de campo e da perspectiva esquizoanalítica, os desafios de efetivar um trabalho a favor da vida, uma vez que somos impelidos, por diversos mecanismos de controle presentes na contemporaneidade, mais à reprodução subjetiva do que propriamente à produção de subjetividades. As produções deste artigo indicam a necessidade de refletir acerca da atuação dos consultores, a fim de minimizar a ação dos mecanismos de controle cotidianos que nos forçam a reproduzir e impactam a nossa potência inventiva.
\end{abstract}

Palavr as-chave: Trabalho. Processos de subjetivação. Cartografia. Esquizoanálise. Desenvolvimento profissional.

\begin{abstract}
This text tries to discuss the processes of subjectivation and their effects on service focused on professional development. Its target is team managers working in engineering companies in the segment of heavy construction. We present the heavy construction market with some of its specificities and we have used a mapping method trying to trace down the processes

\footnotetext{
Texto recebido em julho 2013 e aprovado para publicação em fevereiro de 2014.

"Mestre em Psicologia pela PUC Minas; professor da Faculdade Pitágoras de Betim; consultor, tendo a sua experiência direcionada para a condução de processos de desenvolvimento profissional com gestores que trabalham em empresas de Engenharia e, também, para trabalhos de consolidação de cultura organizacional e desenvolvimento da liderança nos clientes atendidos. Endereço: Rua Eli Seabra Filho, 345/1802 - Buritis, Belo Horizonte-MG. CEP: 30575-740. E-mail: allobatista@oi.com.br. ** Doutora em Psicologia Clínica pela PUC SP, bolsista de Produtividade do CNPq, professora adjunta III do Instituto de Psicologia da PUC Minas. Endereço: Rua Terra Nova, 101/401 - Sion, Belo Horizonte-MG. CEP: 30315-470. E-mail: robertaroma@uol.com.br.
} 
of subjectivation that occur between the consultant and their client in the relationship that is established. We try to discuss throughout our experience, from researching data collected and the schizoanalytical perspective, the challenges of executing a job in favor of life, since we are driven by different control mechanisms present in the contemporaneousness, more subjective reproduction rather than the production of subjectivities. The production of this article shows the need to discuss ways for consultants to act in order to minimize the action of everyday control mechanisms that force us to reproduce and also impact our inventive power.

Keywords: Labor. Processes of subjectivity. Cartography. Schizoanalysis. Professional development.

\section{Resumen}

Este trabajo se propone a discutir los procesos de subjetivación y sus efectos en la atención con foco en el desarrollo profesional que tiene como público objetivo los gestores de equipos de trabajo en empresas de ingeniería del segmento de la construcción pesada. Presentamos el mercado de la construcción pesada con algunas de sus características específicas y utilizamos el método de la cartografía para intentar rastrear los procesos de subjetivación que ocurren entre el consultor y su cliente en la relación que se establece. A través de nuestra experiencia, de los datos de investigación de campo y de la perspectiva esquizoanalítica, buscamos problematizar los retos de realizar un trabajo a favor de la vida, una vez que los mecanismos de control presentes en la contemporaneidad nos impulsan más a la reproducción subjetiva que a la producción de subjetividades. Los resultados de este artículo indican la necesidad de reflexionar acerca de la actuación de los consultores, con la finalidad de minimizar la acción de los mecanismos diarios de control que estimulan la reproducción e impactan nuestro potencial inventivo.

Palabras clave: Trabajo. Procesos de subjetivación. Cartografía. Esquizoanálisis. Desarrollo profesional.

\section{Introdução}

O trabalho é fundamental em nosso cotidiano. Navarro e Padilha (2007) sustentam essa premissa e colocam essa atividade como fonte de desenvolvimento do potencial humano. Na contemporaneidade, essa atividade é enlaçada por um plano de forças muitas vezes opostas. Portanto acreditamos na ideia do trabalho no mundo contemporâneo como algo que, cada vez mais, nos desconstrói e, também, nos constrói, ainda que de forma padronizada, em termos de nossa dimensão subjetiva e singular. Isso porque, para além da materialidade dos produtos, somos impelidos a consumir, com baixo nível de crítica e progressivamente, modos estereotipados de existência ofertados pelo mundo do 
trabalho que, lastreado pela lógica do capital, é forte elemento de modulação e construção tanto da realidade quanto da subjetividade.

A motivação básica de um trabalho que pretende atuar em prol do desenvolvimento humano e que se exerce livre (pelo menos parcialmente) das amarras da sobrevivência indica estar associada exatamente com a perspectiva de se constituir como uma subjetividade autônoma e transformadora do mundo em que se vive. Estamos falando de uma atividade que tem dono, e o seu dono é o próprio trabalhador que, ao produzir, faz diferença para si mesmo e para a coletividade em que se encontra. Embora isso nos pareça mais um ideal utópico a ser perseguido do que algo realmente praticável na contemporaneidade, resta como uma reflexão significativa que se mostra relevante para, ao menos, atenuar os efeitos sutis e cada vez mais vigorosos dos mecanismos de controle da subjetividade, que imperam nesse mundo em que vivemos. Vejamos o entendimento do que significa trabalhar na percepção de uma das consultoras que entrevistamos.

Eu entendo que trabalhar não é apenas produzir. Trabalhar é você transformar a si mesmo em determinadas situaçôes e o processo de desenvolvimento profissional deve funcionar como uma ferramenta nesse sentido, na medida em que ele te sinaliza determinadas situações em que você vai precisar lidar com essas transformaçôes. Ele abre essa perspectiva nessa linha.

Concordamos com a consultora acima tanto no que se refere ao entendimento que ela demonstra acerca do que deve ser o trabalho na vida das pessoas quanto no que concerne à sua visão sobre o trabalho que realizamos na consultoria, como uma ferramenta que deve funcionar para viabilizar processos de transformação. Há quase dez anos, desenvolvemos a atividade de consultoria dentro do mercado de construção pesada, tendo como clientes exatamente os gestores que conduzem a operação desse negócio. $\mathrm{O}$ mercado de construção apresenta significativa relevância para o desenvolvimento do Brasil. Podemos destacá-lo por ser um dos setores mais dinâmicos da nossa economia e também por sua intensa capacidade de absorção de mão de obra direta. A despeito disso, esse mercado convive com dificuldades para conquistar bom nível de produtividade em razão de diversos fatores, e alguns deles se relacionam com características inerentes ao setor. Frej e Alencar (2010) apontam o aspecto não homogêneo e não seriado de produção nesse contexto. Essa característica se dá devido à singularidade do produto, feito sob encomenda, à dependência de fatores climáticos no processo construtivo e ao parcelamento da responsabilidade entre várias empresas, em que o processo de subcontratação é comum. Assim: 
A indústria da construção civil no Brasil ainda é conhecida pelo atraso nos procedimentos gerenciais e técnicas construtivas, pela mão de obra desqualificada, por baixos indices de produtividade, por atrasos nos prazos de entrega, pela não conformidade e pela baixa qualidade do produto final, entre outras limitações. Isso justifica a preocupação atual de um grande número de construtoras com seus sistemas de gestão. A necessidade gerencial na construção civil exige o emprego de ferramentas apropriadas para esse ambiente especifico (Frej \& Alencar, 2010, p. 323).

Os exemplos de limitações do mercado da construção civil retratados anteriormente aparecem na forma de adversidades que, claro, emperram o processo produtivo das empresas desse setor. Por exemplo, a baixa qualificação da mão de obra, sobretudo operacional, leva a uma dilatação do tempo de entrega dos empreendimentos, o que sempre acarreta aumento de custos que nem sempre podem ser repassados para o cliente. Estamos falando, então, de um círculo vicioso de ineficiência que onera o custo final e impacta no resultado a ser conquistado. Portanto existe uma demanda cada vez mais crescente de investimentos relacionados à gestão de seus respectivos negócios por parte das construtoras.

Em nosso trabalho cotidiano, lidamos com o público que tem a responsabilidade de gerir equipes situadas na linha de frente do processo produtivo das construtoras que são nossas clientes. Quando propomos reflexôes acerca de seus respectivos estilos gerenciais e características pessoais, pretendemos contribuir para que os gestores se questionem e se desenvolvam ou se reinventem, sobretudo no que se refere à habilidade relacional e reação sob pressão em um contexto habitualmente repleto de demandas diversas e simultâneas. Entre os problemas que os gestores por nós atendidos enfrentam está a escassez de recursos humanos, sobretudo qualificados.

Assim, além das habilidades técnicas próprias de seu campo de atuação (Engenharia), os gestores que atendemos precisam atuar intensamente na formação e desenvolvimento de substitutos no que se refere, por exemplo, à habilidade de trabalhar em equipe, tomada de decisão e visão, a mais abrangente possível, do próprio papel e escopo de responsabilidade. Ou seja, atuamos para estimular que nossos clientes desenvolvam cada vez mais o entendimento de que não basta fazer a obra, é fundamental, ainda, geri-la.

É exatamente com o intuito de facilitar o desenvolvimento profissional de nossos clientes em seus contextos de trabalho específicos que buscamos construir uma relação que nos permita intervençôes estimuladoras da mudança de atitude, no dia a dia. Cabe salientar que, em nosso trabalho, estamos atentos 
à especificidade do setor, à particularidade de cada empresa e à singularidade de cada caso e das pessoas envolvidas, buscando problematizar os processos de subjetivação existentes, a partir dos encontros entre o consultor e o seu cliente na tentativa de rastrear as forças que estão presentes nessa relação.

$\mathrm{Na}$ dimensão que se estabelece nesses encontros, campo de efeitos e forças, com certeza, vários elementos circulam, afetando as subjetividades envolvidas. Entre esses elementos complexos, alguns são instituídos e estratificados e outros são fluidos e invisíveis, mas nem por isso deixam de produzir efeitos. A cultura organizacional da empresa, certamente, é um desses elementos instituídos que, muitas vezes, submete o gestor que se encontra em atendimento às suas crenças e valores, além de cercear e atravessar o trabalho do consultor. Conhecer essa cultura é também problematizar acerca da atuação do consultor no contexto em questão, uma vez que nosso trabalho visa, em última análise, a inserir as pessoas em uma determinada cultura organizacional, que pode ser compreendida como:

A cultura organizacional deve ser vista, simultaneamente, como um texto polissêmico - que os individuos escrevem e reescrevem por intermédio de suas interaçôes cotidianas dentro $e$ fora do espaço organizacional - e um contexto dentro do qual interpretam e dão sentido às suas experiências no universo do trabalho. Ela não pode ser entendida senão como um palco de disputas, um complexo jogo politico entre atores sociais portadores de diferentes capitais econômicos, culturais e simbólicos, recursos que são distribuídos de forma desigual na estrutura da sociedade, configurando, assim, distinções, desigualdades sociais. Desigualdades estas que, dialeticamente, refletem-se e atualizam-se nas organizaçōes (Jaime, 2002, p. 82).

Por um lado, a cultura organizacional à qual nos referimos se constrói exatamente com base nas interaçôes cotidianas das pessoas dentro e fora do espaço da empresa, o que certamente as auxilia a dar sentido às suas respectivas experiências e expectativas no universo do trabalho. Mas, por outro lado, quando falamos que o nosso trabalho visa a contribuir para a inserção dos profissionais atendidos dentro de uma cultura organizacional específica, estamos considerando que essa cultura vem do dono da empresa, pois são empresas familiares de médio porte. Essa cultura organizacional é expressa por meio de um conjunto de crenças e valores que ele (o dono da empresa) faz questão de formalizar e disseminar como algo instituído, inicialmente, para toda a sua equipe estratégica, com o intuito de facilitar, em um segundo momento, o entendimento e absorção por todos os demais colaboradores.

De fato, os profissionais que atendemos devem ser percebidos em todas as suas interfaces como legítimos representantes dos valores da empresa em que se encontram. No geral, isso ocorre até porque estamos falando de colaboradores que construíram, ao longo dos anos de trabalho, uma relação de confiança e até 
de amizade, em alguns casos, com os donos das empresas em que trabalham. Todavia há também profissionais em posições estratégicas que nem sempre são exemplos de sintonia com a cultura organizacional na qual se encontram. Tal estado de coisas pode se revelar, inclusive, um entrave à permanência deles na empresa e costuma ser tema de diálogos e problematizaçôes que ocorrem no encontro que estabelecem com o consultor.

Em conformidade com nossa prática, as atitudes que almejamos despertar nas pessoas as quais atendemos não pretendem estabelecer um confronto entre seus valores e os da organização da qual fazem parte, mas sim convocar, nessa relação, uma postura inventiva e não apenas adaptativa.

Podemos dizer que, habitualmente, trabalhamos para estimular questionamentos e comportamentos que priorizem a disponibilidade para um trabalho efetivamente em equipe, com visão do resultado a ser conquistado e flexibilidade para assimilar as diferenças individuais, principalmente em meios nos quais a gestão de conflitos e a capacidade para absorver pressão sejam imprescindíveis. Sustentar o coletivo e as diferenças, às vezes, conduz a deslocamentos subjetivos que alteram os membros da empresa e a nós mesmos, em uma dimensão imanente em que o instituído coexiste com o novo.

Dessa forma, a relação que se instaura entre o profissional atendido e a cultura organizacional que ele representa e, principalmente, os desdobramentos de seu encontro conosco são essenciais, pois são nesses "meios" que ocorrem os processos que procuramos cartografar. Observamos que, no percurso de intervenção profissional, em certas circunstâncias, as subjetividades envolvidas no processo são afetadas, podendo ocorrer deslocamentos e transformações, verdadeiros processos de subjetivação. A nosso ver, o enquadre primordialmente adaptativo da consultoria, em sua necessidade de atender à cultura organizacional circunscreve, sim, mas não delimita plenamente o que poderá circular entre o consultor e o seu cliente. Isso porque esse encontro não se caracteriza por ser um caminho linear; pelo contrário, em nossa experiência, a todo o momento, estamos problematizando e tentando rastrear relações complexas que se constroem enviesadas. Nesse sentido, percebemos uma coexistência de forças que ora tendem a reproduzir, ora tendem a fazer surgir outra coisa das relaçóes que se estabelecem no processo de desenvolvimento profissional e dos agenciamentos que daí derivam e que, sem dúvida, produzem efeitos.

Buscamos rastrear neste artigo os efeitos que ocorrem no encontro do consultor e seu cliente, explicitando suas forças, sejam elas adaptativas e, ou, transformadoras, nessa relação. As nossas tentativas de explicitação desses efeitos não têm necessariamente uma ambição explicativa, mas sim cartográfica, no 
caminho de apontar a coexistência dos momentos em que a vida se expressa como potência de invenção com aqueles nos quais ela se encontra, de alguma forma, estancada, capturada, estratificada. Nesse percurso, utilizamos o método da cartografia e a noção de subjetividade proposta por Deleuze \& Guattari (2010), operadores que nos permitem abarcar a complexidade e a processualidade do nosso objeto de estudo.

De acordo com (Romagnoli, 2009), a cartografia é um método de pesquisa que se opõe a um pensamento dicotômico, insistindo na complexidade do objeto de estudo. Esse método concebe a complexidade indissociável da processualidade da pesquisa, evidenciando as forças que atuam transversalmente sobre o pesquisador e sobre o objeto de estudo, perseguindo o heterogêneo. Nesse sentido, o papel do pesquisador é fundamental, pois é por ele que a realidade vai se fazer e as forças vão pedir passagem. Para tanto, Rolnik (2006, p. 65) atesta que "O cartógrafo é um verdadeiro antropófago: vive de expropriar, se apropriar, devorar e desovar, transvalorado".

Parece-nos que a cartografia envolve uma atitude particularmente atenta aos movimentos de expansão e de aprisionamento da vida para que sejam possíveis, para além da explicação e do controle, diversas construções de possibilidades de sentidos na relação do pesquisador com o seu objeto de estudo. Ambos são transformados, e o conhecimento, nessa abordagem, constrói-se nessa relação. Nesse sentido, a produção de conhecimento não é um dado a priori, mas pode ser gestada por conexões que sejam potencializadoras e a favor da vida.

Acolher a vida em seus movimentos de expansão pode se dar por uma postura de aceitação do inusitado e das possibilidades que compõem a realidade com a qual nos deparamos. Passa pelo entendimento de que o nosso "objeto de estudo" não precisa estar apartado de nós (até porque ele não está) e não estará estático à espera que possamos decifrá-lo, sabendo que as respostas encontradas são provisórias e circunstanciais. Aliás, cartografar não parece ser decifrar, mas sim se construir enquanto se constroem perspectivas de conhecimento.

Balizados pelo interesse em construir sentidos diversos na relação que se estabelece entre o consultor e o seu cliente, partimos para o campo, a fim de efetivarmos a nossa pesquisa, enfatizando os atravessamentos e desdobramentos possíveis nos processos de subjetivação presentes nesse contexto. O nosso trabalho se deu por meio de entrevistas semiestruturadas, com consultores que atuam em atendimentos voltados para desenvolvimento profissional, nossos colegas, e com profissionais que já se submeteram a esse tipo de trabalho. Foram entrevistados três consultores seniores e três profissionais. O principal critério que justifica a escolha desses dois grupos de pessoas é exatamente o entendimento de todos eles 
sobre o que vem a ser o processo de desenvolvimento profissional. As reflexões ou construções efetuadas neste estudo são apresentadas as seguir.

\section{Compreendendo os processos de subjetivação e a sua articulação com o dia a dia de trabalho do consultor}

Deleuze \& Parnet (1998) insistem que a subjetividade é imanente a um campo social composto também por linhas de virtualidade, situaçôes e agenciamentos. $\mathrm{O}$ agenciamento é um conceito central nessa proposta, pois desloca a subjetividade da interioridade e lança no coletivo. $\mathrm{O}$ agenciamento associa o plano de organização, que corresponde à dimensão da realidade que cristaliza e captura os fluxos da vida, visível e estabelecida, e o plano de composição que sustenta uma dimensão de forças não necessariamente visíveis, mas que, ao serem experimentadas, traçam desvios, modificam situações e, enfim, produzem subjetividades. É no plano de composição que se dão as conexôes entre os fluxos, os agenciamentos que vão gerar novos sentidos, novas formas de expressão que escapam aos modelos do plano de organização. Esses planos coexistem e se distinguem pelo seu funcionamento.

Se, por um lado, o plano de organização tem um funcionamento segmentar, o plano de composição, por sua vez, tem um funcionamento fluido e conectivo, que se liga ao coletivo, ao que está fora de cada elemento que o compóe. Esse arremesso na exterioridade permite a atualização do virtual, do que existe em potência e não em ato, em cada situação e que ganha consistência nas relações, no que se estabelece "entre" as subjetividades envolvidas, no caso, no encontro entre consultor e cliente. Esse aglomerado de forças que acompanha os encontros emerge nas relaçôes e também faz parte da subjetividade cuja composição é heterogênea.

Esse estado de potência inerente à realidade e a todos nós, como virtualidade, atualiza-se na dimensão invisível que se forma em nossas relações, nos encontros que fazemos, sejam eles profissionais ou não. Assim, podemos salientar a importância deles para a invenção, ao criar uma dimensão "entre" na qual as linhas de virtualidade podem ser atualizadas. Quando as subjetividades se encontram, há o estabelecimento de uma relação que pode ter efeitos distintos. Ao estudar como se dão esses encontros, baseada em uma perspectiva deleuziana, Romagnoli (2003) defende a ideia de que não podemos nos definir como sujeitos separados das relações que estabelecemos, até porque nos construímos uns aos outros nesse "entre" relacional. Nossos encontros pela vida afora podem ser vigorosos, aumentando a nossa potência de existir, mas podem também nos fazer padecer e minar as perspectivas de nos lançar rumo ao novo, ao inusitado. 
Podemos dizer, assim, com base em uma leitura conectiva e processual, que somos o que compomos ou o que decompomos de nós e dos outros a partir dos encontros que vamos fazendo. No caso específico do nosso trabalho de consultor, estamos falando de encontros que se dão no meio profissional, mas nem por isso deixam de conter elementos virtuais que podem se potencializar dependendo dos agenciamentos feitos. Se pudermos criar um espaço nesse "entre" relacional, outra dimensão da qual façam parte consultor, cliente, cultura organizacional e demais aspectos externos que atravessam essa relação e sobre os quais não temos controle, seremos convocados a nos deslocar, a dar passagem a determinadas forças, ainda que façamos uso de ferramentas de trabalho que tentam capturar, descrever e estancar a dinâmica subjetiva do profissional atendido e formalizar o nosso conhecimento de psicólogo, de consultor que sabe sobre o outro. Entendemos que o nosso desafio é construir um espaço de conexão com o profissional atendido, a fim de que não nos tornemos aderidos em demasia aos nossos relatórios e demais instrumentos de captura da singularidade alheia, embora não possamos desconsiderar que essa dimensão da realidade também define o nosso papel nessa relação e deixa fortes impressões nos profissionais que atendemos.

O trabalho se torna possível a partir da consolidação da relação e do entendimento dos papéis do consultor e do profissional atendido, daí estarão lançadas as bases para que se construa uma reflexão que leve ao questionamento de uma determinada posição subjetiva e, consequentemente, a um deslocamento, ainda que esta possa se dar, em parte, no rumo da inserção em uma cultura organizacional específica. Nesse contexto, o ganho para o nosso cliente tende a estar relacionado com o aprimoramento da capacidade de crítica, inclusive, acerca das forças opressoras que incidem sobre as relações de trabalho de uma maneira geral e, claro, das relações de trabalho a que ele especificamente se encontra submetido.

É preciso salientar que, como gestor de equipes, o nosso cliente é porta-voz dos anseios do dono da empresa em todas as suas interações e interfaces. Quanto mais clareza tiver acerca disso, mais ampliada poderá ser a sua perspectiva de resistir (no sentido deleuziano do termo). Essa ideia de resistência associa-se à noção de inventividade na maneira de lidar com a vida e com o trabalho que nela se encontra inserido. Romagnoli (2007) explicita bem essa noção da vida como uma potência que desloca subjetividades conforme estas se relacionam com forças externas, inaugurando outros territórios existenciais. Podemos acrescentar aqui a ideia de que tal empreitada tende a se tornar menos árdua quando somos capazes de evitar posturas que nos deixem excessivamente cristalizados em nossos respectivos papéis, crenças, visão de mundo, e nos arriscamos a conectar com outras forças. 
Assim, falar de processo de subjetivação é raciocinar com base na exterioridade e no coletivo, nas forças externas que nos atravessam e nos impelem à invenção. Sustentar essa perspectiva em nosso trabalho cotidiano envolve o desenvolvimento de uma postura sempre vigilante na lida com o nosso saber e suas respectivas implicações na relação, uma vez que esta também contempla dimensões virtuais, ou seja, que não podemos conhecer, a priori. Nesse sentido, nosso encontro com os nossos clientes pode possibilitar a experimentação e dar corpo às intensidades e afetamentos para inventar novos caminhos. Essa possibilidade de experimentação pode ou não emergir nesse processo, sobretudo pela atitude que assumimos.

Acolher o plano de forças que pode brotar da situação de atendimento faz com que o consultor não se coloque como onipotente e controlador de todo o processo. É essa a dimensão subjetiva que pode ser revelada nos atendimentos com foco no desenvolvimento profissional, se o que se quer é o espaço à experimentação. Se nos apresentamos como aquele que tem um saber válido, que é usado para potencializar e não para oprimir, seremos capazes de dar voz ao profissional que atendemos para que ele reinvente e desloque a sua própria posição subjetiva. Dessa forma, podemos trazer para o nosso cotidiano de consultor a dimensão de virtual que pode emergir em nossas relaçôes sustentando um plano não hierárquico.

Nesse processo é preciso cautela com o poder que o cliente normalmente atribui ao consultor. Observamos que uma das formas de minimizar a tendência à idealização do papel do consultor por parte dos clientes está relacionada exatamente com a questão de deixar aparecer essa dimensão de virtualidade, guardando, em contrapartida, certa distância que assegure o enquadre necessário à efetivação do trabalho pretendido. Talvez o cultivo de uma atitude mais espontânea na relação que se estabelece possa nos ajudar a encurtar a distância e a hierarquia que o poder (saber) a nós atribuído por nossos clientes costuma potencializar. Nesse sentido, vejamos a fala de um dos nossos entrevistados.

Eu acho que, na maior parte do tempo, favorecem muito a qualidade e a intensidade da interação que estabelecemos. Eu vejo mais ganhos do que a questão de desfavorecer a captura da pessoa. Essa vinculação desmitifica um pouco. Talvez, mais do que desmitificar, esse clima de proximidade faz com que o profissional se sinta próximo também, e eu tenho uma questão de achar que a gente fica mais humana do que aquele profissional de psicologia, de consultório, tipo psicanalista.

Certamente, a vida também é feita de certezas e de repetições que, de alguma forma, tentam organizar sua heterogeneidade. Mas, se estamos falando de processos de subjetivação inventivos, precisamos ser capazes de desestabilizar 
crenças e fazer pensar, e esse nos parece ser um movimento que, na situação de atendimento, precisa ser disparado pelo consultor. Fazer isso pode significar, por exemplo, exercitar uma atitude menos convicta acerca das próprias verdades e rechaçar o lugar de sábio. Assim, diríamos que é possível estar mais disponível para o não saber, para o imprevisível que é o contato com o outro, com as forças, fluxos e agenciamentos próprios do plano de composição (Deleuze \& Parnet, 1998).

Um atendimento que se inicia é sempre uma incógnita, sobretudo para o consultor que está aberto a pensar em função das desestabilizações que uma nova situação traz em seu arcabouço de possibilidades. É preciso estranhar e nos perguntar continuamente se seremos capazes de nos conectar com os profissionais que atendemos, para que possamos afetar e ser afetados, deslocar e ser deslocados, conforme abdicamos do excessivo apego ao que conhecemos e dominamos.

Quando estranhamos alguma situação e damos passagem para o inusitado sem a pretensão de necessariamente decodificá-lo, estamos nos abrindo para as forças do plano de composição, que é onde se dá a invenção e a mudança de posição subjetiva que ela pode fazer surgir. E podemos atuar como intercessores nesse processo de deslocamento subjetivo. A noção de intercessor assinalada por Deleuze (1992) remete à aposta nos encontros, no "entre" como espaço de criação e invenção. $O$ intercessor permite que algo se desloque e que a subjetivação aconteça. Pontos que tentamos convocar em nosso trabalho.

\section{O processo de desenvolvimento profissional: transcendências e imanências}

Acreditamos que é viável estabelecer uma relação com nossos clientes na qual coexistam a invenção e a adaptação. Já sinalizamos posturas que o consultor pode adotar para dar corpo ao inédito dentro da situação de atendimento. Mas, agora, queremos explicitar quando, claramente, o consultor sustenta a relação de transcendência e atua em prol da adaptação, insistindo na reprodução. Sustentados por Deleuze (2011), podemos dizer que a transcendência se opõe à imanência que não remete a nenhum tipo de hierarquia, visto que não reproduz modelos teóricos preconcebidos por meio dos quais poderíamos chegar à "verdade", por exemplo, sobre o nosso objeto de estudo, independente da sua natureza. Pensar a realidade com base na ideia de transcendência implica manter-se aderido, por exemplo, a conceitos prévios de como as coisas são ou de como devem ser. Sugere o estabelecimento de relaçôes hierárquicas e assimétricas, porque enfatiza a supremacia do sujeito que sabe sobre o objeto a ser conhecido, do consultor que tudo conhece acerca do seu cliente. Sabemos que modelos e representações 
ou imagens da realidade compõem o nosso cotidiano e não podemos nos furtar de considerar esse estado de coisas. Mas o ato de pensar, no sentido deleuziano, como também exercitamos neste artigo, implica o movimento de lançar novos olhares e perspectivas sobre uma determinada situação, o que parece associar-se mais intimamente à concepção de imanência. Conforme Schöpke (2004), essa é a originalidade cognitiva na visão tanto de Deleuze quanto de Nietzsche.

O "novo", tanto em Nietzsche quanto em Deleuze, é aquilo que ativa o pensamento, que o força a "pensar", que o impele a agir (sendo que a ação do pensamento é a sua própria criação). Em Proust e os signos, Deleuze fala da atividade do pensamento como algo extraordinário e não como resultado de um "interesse natural". "Nós só procuramos a verdade quando estamos determinados a fazê-lo em função de uma situação concreta, quando sofremos uma espécie de violência que nos leva a essa busca". Isso quer dizer que "pensar" não é uma tendência natural, mas é efeito de uma força externa que nos violenta, retirando a razão de sua função recognitiva (Schöpke, 2004, p. 32).

Nessa perspectiva, nós, consultores, corremos o risco de não pensar (e de apenas reproduzir conhecimentos e conceitos alheios) quando nos contentamos com o papel de porta-vozes de uma cultura organizacional, sem nos preocuparmos em disparar conexões, críticas construtivas, enfim, fazer pensar. Problematizar essa dimensão de transcendência que aparece em nosso trabalho por meio de intervenções que visam à adaptação e reforçam o nosso lugar de poder é fundamental, exatamente para que possamos minimizá-la e fazer pensar. Vejamos a fala de uma colega.

Sobre certos aspectos, vejo como um adestramento. Inclusive, eu lembro que, quando comecei a trabalhar, focava mais no comportamento do sujeito. Hoje, eu vejo em meus atendimentos que o foco está mais no sujeito, não na mudança do comportamento em si, mas na mudança do comportamento como consequência. Procuro trabalhar com ele na linha da percepção de que o processo de desenvolvimento profissional pode trazer algo de produtivo, seja dentro daquele contexto organizacional ali ou de qualquer outro contexto organizacional em que ele esteja. Tento levá-lo a pensar se o que está sendo proposto é alguma coisa que violenta demais. Aí você encontra diversas respostas.

Deleuze e Guattari (2010), ao introduzirem a esquizoanálise, ressaltam que esta tem duas tarefas fundamentais: a raspagem ou curetagem, e a produção de dispositivos. A raspagem ou curetagem corresponde a uma crítica ao modus vivendi atual, fundamentada pela concepção de mundo e de subjetividade dessa proposta, que critica toda e qualquer hegemonia e aposta na exterioridade. Essa crítica ocorre em conjunto com a produção de dispositivos que se referem à efetivação de novas maneiras de viver e de pensar. Produzir dispositivos é burlar 
a transcendência, o poder opressão e instalar outro tipo de poder, que é o poder potência. Nesse sentido, pesquisar o desenvolvimento profissional é operar ao mesmo tempo nessas duas dimensões. No entanto, a invenção está atrelada à crítica. Assim, é importante que nós, consultores, problematizemos a nossa prática com a máxima humildade que nos seja possível, pois, balizados em nossa experiência, podemos dizer que isso ainda ocorre pouco e, portanto, dificulta a ascensão de um olhar que seja realmente original, singular sobre o nosso dia a dia. Os motivos dessa situação tendem a ser vários e não é nossa proposta discutilos aqui. De toda forma, devemos concordar que é muito difícil questionar o que fazemos e quem são nossos senhores, pois nossos ganhos e realizações são sustentados, muitas vezes, pela relação que estabelecemos com o nosso trabalho e com o mundo do trabalho de uma forma geral, que, por sua vez, está lastreado pelo capital que a nosso ver direciona e prescreve posturas, sim. Esse é mesmo um atravessamento que permeia nossas conexões e não pode ser desconsiderado em nosso cotidiano de trabalho, somente entendemos que ele não deve servir de estímulo para a ascensão e cristalização de posturas desprovidas de crítica.

Baseados em nossa experiência profissional, podemos dizer que a tendência dos clientes para colocar o consultor no lugar de um orientador é bem comum, sobretudo quando a relação que se estabelece já se encontra mais sedimentada. Isso é mesmo importante: algumas vezes, os clientes partem de uma situação inicial de desconfiança em relação ao consultor, ao seu papel específico na situação de atendimento. Depois de um curto período, quando a relação de confiança já está estabelecida, tornam-se mais receptivos às nossas intervenções e tendem a nos idealizar como aqueles que sabem. As coisas parecem ir de um polo a outro: em um primeiro momento, alguns clientes correm o risco de exceder na desconfiança e na desconsideração de um trabalho que, na verdade, ainda nem conhecem. Em um segundo momento, o risco parece estar mais associado à possibilidade de exacerbarem no entendimento e na crença de que o consultor tem todos os elementos para entender as suas respectivas dinâmicas psicológicas e promover as respostas de que necessitam. Essa percepção apareceu nas falas de nossos entrevistados.

Essa dinâmica de desenvolvimento da relação que se estabelece tem, certamente, o seu lado satisfatório já que é gratificante quando nós, consultores, conseguimos conquistar a confiança de alguém que, a princípio, tendia a desacreditar do nosso trabalho. No entanto é preciso ter cuidado para não alimentarmos a nossa vaidade, de maneira a ficarmos tão encantados a ponto de comprometer certo nível de lucidez que nos parece imprescindível para que sejamos capazes de disparar conexões que favoreçam o surgimento de processos de subjetivação inventivos. Caso contrário, nós, consultores, corremos o risco 
de nos tornar meros orientadores (adestradores) focalizados apenas na tarefa de inserir e adaptar os profissionais que atendemos à cultura organizacional em que se encontram.

Por tudo o que ponderamos até aqui, é possível afirmar que o nosso cotidiano de consultor a serviço das empresas com suas respectivas culturas organizacionais já traz, a priori, para o nosso trabalho, exigências relacionadas com o plano de organização composto de funções e expectativas, e isso pode alimentar uma espécie de exacerbação da relação de transcendência, que parece excluir a possibilidade de um processo de subjetivação inventivo. Portanto o nosso grande desafio continua sendo o de pensar e, claro, fazer pensar para que sejamos disparadores de ações de resistência. Isso nos parece possível a partir do momento em que começamos a trabalhar no dia a dia, considerando, sim, a nossa função contratada de porta-vozes dos donos das empresas em relação à disseminação de uma cultura organizacional específica, mas atentos à nossa responsabilidade ética de fazer pensar. Esta pode ser facilitada pelo estabelecimento da confiança na relação que se efetiva, pois, assim, os profissionais atendidos começam a se colocar e criamos as bases para que ambas as expectativas (da empresa e do profissional atendido) sejam abordadas e problematizadas no contexto de atendimento no qual nos encontramos inseridos. Nesse sentido, vejamos a fala de uma das consultoras entrevistadas.

A minha principal expectativa é que a relação de confiança que se estabelece entre mim e a pessoa com a qual estou trabalhando seja fator gerador de uma transformação, de uma mudança de comportamento que possa viabilizar a adequação entre as duas expectativas, a da empresa e a do profissional, porque não seria satisfatório atender a um objetivo da empresa sem adequar à necessidade do outro.

Temos falado da coexistência entre movimentos adaptativos e deslocamentos subjetivos que compóem o percurso do processo de desenvolvimento profissional. Por acreditarmos que não devemos alimentar polarizações e nem hierarquias entre esses dois processos (adaptação e deslocamento subjetivo) é que iremos nos valer, a partir de agora, da ideia de imanência como elemento norteador da nossa linha de raciocínio e argumentação. Segundo Deleuze (2011): "A imanência não se remete a alguma coisa como unidade superior a todas as coisas nem a um sujeito como ato que opera a síntese das coisas: é quando a imanência é imanência apenas a si que se pode falar de um plano de imanência”.

O entendimento do raciocínio em questão parece demandar a supressão das dualidades e da ideia de que haveria um sujeito separado do objeto e que, 
por assim ser, pudesse pensá-lo. Talvez possamos pensar que sujeito e objeto se constroem em relação e, portanto, não faria sentido defender a supremacia de um em relação ao outro. Nessa perspectiva, é possível pensar o processo de desenvolvimento profissional não apenas como a interação do sujeito que conhece (consultor) com o objeto a ser conhecido (cliente). Mas o compreender balizado pela lógica da imanência parece significar que, no processo de desenvolvimento profissional, assim como na vida, estamos em um constante processo de produção de subjetividades, que, ao se relacionarem, modificam-se e se engendram mutuamente. A imanência leva necessariamente à experimentação e ao inédito, mas também faz referência a estratificações e capturas. A imanência parece se traduzir em um emaranhado de possibilidades que existem exatamente porque se produzem simultaneamente, sem que haja espaço somente para dicotomias e hierarquias ou primazias de um termo ou objeto sobre outro.

$\mathrm{Na}$ verdade, esse é apenas um modo de funcionamento da realidade, que pode ser pensada como rizoma. Parpinelli e Souza (2005) destacam: "O rizoma é um conceito que entende a realidade - e dentro dela a própria subjetividade - como uma rede constituída de inúmeras ramificações que se conectam e reconectam continuamente com outras ramificaçôes" (p. 480).

As inúmeras ramificações do conceito de rizoma remetem às linhas que se constroem conforme nos lançamos na aventura de trabalhar (e viver) balizados pelo entendimento de que as subjetividades são construídas na relação com o externo, com o que vem de fora e nos força a conceber outros sentidos à nossa experiência cotidiana. Entendemos que efetivar um raciocínio pautado na concepção de rizoma implica em um processo de investigação infindo das perspectivas de olhares e sentidos inusitados que podemos lançar sobre a realidade na qual estamos inseridos.

É preciso frisar que isso é bem diferente de se ocupar, prioritariamente, com a questão de achar "respostas" para os desafios que o dia a dia coloca em nosso caminho. $\mathrm{O}$ pensar rizomático implica em se ater às conexóes possíveis para se construir caminhos de reflexão e sentidos outros para a realidade que nos cerca. É por isso que esse conceito de rizoma se entrelaça com a ideia de imanência. Entender o mundo que nos cerca e viver com base nesse pressuposto de que a realidade (e a subjetividade) é produzida de possibilidades e de conexões com o que vem de fora parece ser um convite à aventura de não ter respostas a priori. Pode ser muito desafiadora essa questão de alimentar a ideia de se reinventar e se produzir constantemente em vez de apenas se definir como detentor de determinados atributos pessoais, intelectuais e relacionais. Tal posicionamento, no trabalho e na vida, traz incômodo, e entendemos que, para se conduzir o 
processo de desenvolvimento profissional considerando a imanência, é preciso primeiro confrontar-se com as suas implicações na própria subjetividade.

\section{Considerações finais}

Entendemos que nos foi possível, ao longo deste artigo, problematizar alguns atravessamentos e desdobramentos da relação que se estabelece entre o consultor e o seu cliente, ainda que não possamos considerar que foram problematizados todos os aspectos que compóem o contexto do processo de desenvolvimento profissional. $\mathrm{Na}$ realidade, ao iniciarmos este texto, nós nos encontrávamos firmemente imbuídos do intento de provocar reflexóes em nosso leitor, independentemente da sua área de atuação, mas, principalmente, nos colegas que também se dedicam à atividade de consultoria.

Nesse sentido, gostaríamos que o nosso trabalho provocasse questóes e estimulasse o pensamento do consultor em algumas direções que, esperamos, levem-no a evocar, em diversos momentos, perguntas sobre o sentido do trabalho tomado como uma atividade constitutiva do ser humano e, mais especificamente, sobre o sentido do trabalho de consultoria como considerado em nossa discussão. E, quem sabe, essas perguntas, atuem para o engendramento da raspagem ou curetagem, proposta por Deleuze e Guattari (2010) como uma das tarefas da esquizoanálise, criticando a forma estabelecida de se trabalhar com o desenvolvimento profissional. Raspagem ou curetagem que ocorre em consonância com a produção de dispositivos para a criação de novas maneiras de pensar e de viver. Processo que pretende driblar a transcendência e apostar na imanência.

Procuramos também situar o conceito de cultura organizacional, em razão do fato de que o nosso trabalho se constrói ancorado na necessidade de clarear o seu entendimento e estimular a adesão dos profissionais que atendemos à respectiva cultura em que se encontram. Mas é necessário frisar que tentamos fazer isso perseguindo posturas inventivas e não apenas adaptativas. Aliás, foi essa a reflexão que embasou toda a nossa discussão. Em diversos momentos deste trabalho, tentamos rastrear os movimentos de adaptação e de invenção que ocorrem ao longo do processo de desenvolvimento profissional, por acreditarmos que sustentar o coletivo e as diferenças, às vezes, conduz a deslocamentos subjetivos que alteram os membros da empresa e a nós mesmos, consultores, em uma dimensão imanente em que o instituído coexiste com o novo.

Tentamos problematizar a nossa percepção inicial de que o enquadre primordialmente adaptativo do trabalho que desenvolvemos na consultoria para atender à cultura organizacional circunscreve, sim, mas certamente não delimita 
plenamente o que poderá circular entre o consultor e o seu cliente. Procuramos caracterizar situaçôes em que a coexistência de forças que ora tendem a reproduzir, ora tendem a fazer surgir o inédito ficassem claras, inclusive com a participação direta do consultor, que tem, a priori, a tarefa de adaptar, mas que, como vimos, é capaz de trabalhar em prol, também, de fazer pensar.

Como já comentamos, este estudo não pretendeu abarcar todos os aspectos presentes na relação que se estabelece ao longo do processo de desenvolvimento profissional. Mas teve uma meta muito clara: problematizar caminhos de reflexão para que nós, consultores, possamos agregar algum nível de originalidade ao trabalho que fazemos, conforme conseguimos atuar em prol de processos de subjetivação inventivos. Entendemos que lançamos questôes para fazer pensar e, em hipótese alguma, para esgotar a temática. Caso o consultor que atua com desenvolvimento profissional se sinta incomodado e, sobretudo, desafiado pelo nosso texto a lançar outros olhares possíveis sobre a sua prática, acreditamos que teremos chegado ao nosso principal objetivo.

\section{Referências}

Deleuze, G.(1992). Conversaçôes. Rio de Janeiro: Ed. 34.

Deleuze, G. (2002). A imanência: uma vida... Educação e Realidade, 27(2), 1018. Recuperado a partir de http://seer.ufrgs.br/index.php/educacaoerealidade/ article/view/31079/192911

Deleuze, G. \& Guattari, F. (2010). Introdução à esquizoanálise. In: G. Deleuze \& F. Guattari, $O$ anti-Édipo: capitalismo e esquizofrenia. (pp. 285-401). Lisboa: Assírio e Alvim.

Deleuze, G. \& Parnet, C. (1998). Políticas. In: G. Deleuze \& C. Parnet, Diálogos. (pp. 145-170). São Paulo: Escuta.

Frej, T. A. \& Alencar, L. H. (2010). Fatores de sucesso no gerenciamento de múltiplos projetos na construção civil em Recife. Produção, 20(3), 322-334. Recuperado a partir de http://www.scielo.br/pdf/prod/v20n3/aop_200812127. pdf.

Jaime, J. P. (2002). Um texto, múltiplas interpretações: antropologia hermenêutica e cultura organizacional. Revista de Administração de Empresas, 42(4), 72-83. Recuperado a partir de http://www.scielo.br/pdf/rae/v42n4/v42n4a08.pdf. 
Navarro, V. L. \& Padilha, V. (2007). Dilemas do trabalho no capitalismo contemporâneo. Psicologia \& Sociedade, 19(n. esp.), 14-20. Recuperado a partir de http://www.scielo.br/pdf/psoc/v19nspe/v19nspea04.pdf.

Parpinelli, R. S. \& Souza, E. W. F.(2005). Pensando os fenômenos psicológicos: um ensaio esquizoanalítico. Psicologia em Estudo, 10(3), 479-487. Recuperado a partir de http://www.scielo.br/pdf/pe/v10n3/v10n3a15.pdf.

Rolnik, S.(2006). O cartógrafo. In S. Rolnik, Cartografia Sentimental: transformaçôes contemporâneas do desejo. (pp. 65-72). Porto Alegre: Sulinal Editora da UFRGS.

Romagnoli, R. C.(2003). Os encontros e a relação familiar: uma leitura deleuziana. Arquivos Brasileiros de Psicologia, 55(1), 21-30.

Romagnoli, R. C.(2007). A invenção como resistência: por uma clínica menor. Vivência, 1(32), 97-107.

Romagnoli, R. C.(2009). A cartografia e a relação pesquisa e vida. Psicologia e Sociedade, 21(2), 166-173. Recuperado a partir de http://www.scielo.br/pdf/ psoc/v21n2/v21n2a03.pdf

Schöpke, R. (2004). O pensamento como ultrapassamento da representação clássica. In R. Schöpke. Por uma filosofia da diferença: Gilles Deleuze, o pensador nômade. (pp. 19-42). Rio de Janeiro: Contraponto. 